Final draft of Suthers, D. D., Yukawa, J., \& Harada, V. H. (2007). An activity system analysis of a tripartite technology-supported partnership for school reform. Research and Practice in Technology Enhanced Learning, 2(2), 1-29.

\title{
AN ACTIVITY SYSTEM ANALYSIS OF A TRIPARTITE TECHNOLOGY- SUPPORTED PARTNERSHIP FOR SCHOOL REFORM
}

\author{
DANIEL D. SUTHERS, ${ }^{a}$ JOYCE YUKAWA ${ }^{\mathrm{b}}$ AND VIOLET H. HARADA ${ }^{\mathrm{a}}$ \\ ${ }^{a}$ Department of Information and Computer Sciences, University of Hawai i at Manoa, 1680 East West Road, \\ Honolulu, HI 96822, U.S.A. \\ ${ }^{b}$ Library and Information Science, College of St. Catherine, 2004 Randolph Ave., St. Paul MN 55105 \\ suthers@hawaii.edu,jyukawa@stkate.edu,vharada@hawaii.edu
}

\begin{abstract}
School improvement often involves partnerships between multiple stakeholder groups. In order to understand the strengths and challenges of a partnership, it is necessary to examine the objectives and practices of the constituent groups and the forces that shape these practices. This paper presents an activity theory analysis of relationships between three professional communities of practice in a school reform effort, Hawai'i Networked Learning Communities. Essential tensions between the activity systems of the communities are analyzed to understand key issues encountered in the implementation, particularly with respect to the role of technology in mediating a program of professional development.
\end{abstract}

Keywords: activity theory, communities of practice, project assessment, school reform partnerships

\section{Introduction}

School reform - the effort to effect sustainable changes in the functioning of a school system that lead to improved student achievement (Fullan, 2001; Harris, 2005) - is typically undertaken as a partnership among multiple stakeholders (Huffman \& Hipp, 2003; Schlager et al., 2004). For example, the reform initiative that is the topic of this paper, Hawai i Networked Learning Communities (HNLC), is a partnership between university researchers and a state school system that is itself constituted of multiple professional communities. Partners bring not only different strengths to the collaboration but also enact distinct practices under different reward systems and sets of constraints (Hildreth \& Kimble, 2004). In order to understand the strengths and challenges of a partnership, it is necessary to examine the objectives and practices of the constituent communities and the forces that shape these practices. Such reflections on a reform process should be an ongoing affair, conducted not only at the outset or conclusion of a project, but also during implementation as experience provides an empirical basis for further reflection and the identification of problems motivates its urgency.

This paper is the product of ongoing reflection within the HNLC initiative. Several theoretical frameworks have been employed in this reflection. In this paper we report on 
our adoption of concepts from activity theory (Cole \& Engeström, 1993; Engeström, 2001; Kaptelinin \& Nardi, 2006) to identify alignments and tensions between the partner communities that help us understand key issues encountered in the implementation of HNLC, particularly with respect to the role of technology in mediating professional development. Our analysis of tensions within and between activity systems is aided by dualities and other concepts from communities of practice theory (Wenger, 1998). Although HNLC encompasses other activities, the present analysis focuses on a collaborative partnership between university researchers and state education staff for improvement of instructional practices through teacher professional development. We write from our point of view as the university partner, and have grounded our claims about the activity systems of partner communities in evidence including meeting notes, planning documents, project reports, interviews, focus groups, surveys, and online activity. As explained below, we view our partnership as a tripartite one between state district-level staff, school-level educators, and university researchers. This paper will focus on how activity theory and dualities helped us conceptualize and respond to challenges that emerged as these communities worked towards change.

\section{Background}

\subsection{Hawai i Networked Learning Communities}

Hawai ${ }^{i}$ Networked Learning Communities (HNLC) is a Rural Systemic Initiative funded by the US National Science Foundation for planning in 1999-2001 and implementation in 2001-2007. Its goal is to "empower Hawai'i's rural students to achieve excellence in science, mathematics and technology and to develop responsible stewardship in preserving our dynamic cultures and unique island ecosystems." "The initiative involves a partnership between the Laboratory for Interactive Learning Technologies (LILT) within the Department of Information and Computer Sciences (ICS) at the University of Hawai $i(\mathrm{UH})$, and the Advanced Technologies Research (ATR) group of the Hawai $i$ Department of Education (HDOE). The HDOE is the only statewide school district in the United States. Approximately 40 primary and secondary schools have participated in HNLC, having joined the initiative in four successive cohorts starting in 2002.

As a systemic reform effort (Smith \& O’Day, 1991; Blumenfeld, Fishman, Krajcik \& Marx, 2000), HNLC encompasses several lines of work intended to effect sustainable changes in the school system that lead to improved student achievement. Specifically, HNLC has been organized around the "NSF Drivers" (NSF, 2001) for systemic reform, six critical areas that the US National Science Foundation has identified as critical to reform in its systemic reform programs (which include urban and state as well as rural systemic initiatives). The drivers (in brief) are:

- Driver 1: Implementation of comprehensive, standards-based curricula including student assessment.

- Driver 2: Development of a coherent, consistent set of policies that support highquality mathematics and science education and support responsible teachers and administrators.

- Driver 3: Convergence of the usage of all resources designed to support science and mathematics education.

\footnotetext{
${ }^{1}$ From Strategic Plan dated October 23, 2002: other versions exist. Throughout this paper, footnotes will be used primarily to document sources for empirical claims, and need not be read to comprehend the paper.
} 
- Driver 4: Broad-based support from parents, policymakers, institutions of higher education, business and industry, foundations and other segments of the community.

- Driver 5: Accumulation of an array of evidence that the program is enhancing student achievement.

- Driver 6: Significant reductions in the achievement disparities among students that can be attributed to socioeconomic status, race, ethnicity, gender, or learning styles.

However, the present paper focuses on one aspect of the work of HNLC: the attempt to improve teachers' instructional practices through a program of ongoing professional development. This aspect primarily addresses Driver 1 (implementation of standardsbased assessment-driven curriculum), with the support of Drivers 3 (access to resources) and 4 (support from the state and university sectors). The study examines the collaborative partnership between ATR staff and LILT staff toward this end, directed at teachers. The work reported in this paper offers lessons for any collaborative partnership directed at improvements in educational practices, whether or not in a systemic reform context.

Alongside our other roles as project leaders and facilitators, the LILT team provides technology support for the systemic reform effort (Suthers et al., 2004). Our intent is to support the change process itself, especially as manifest in teacher professional development and the collaborative reflection of practitioners. LILT offers information technologies in the form of an interactive web site-hnlc.org - a "virtual community center" that supports collaboration and resource sharing across institutional and geographic boundaries and between isolated rural schools in our island state. The web site was designed to support the needs of special purpose groups with workspaces while embedding them in a statewide virtual community of educators. This "nested community" approach is intended to capitalize on the advantages of larger groups such as resource sharing and potentials for new interpersonal relationships (Joseph, Lid \& Suthers, 2007; Resnick, 2002) while also meeting local needs and enabling negotiability of purpose (Wenger, 1998). Community support includes a membership directory, a database of educational resources particularly relevant to Hawai $i$ educators, and a community forum for news and announcements. For example, the home page for a logged-in user is shown in Figure 1. Smaller groups are supported by workspaces that collect together wiki pages (user-editable web pages), file sharing, and documentcentered discussion tools (to be illustrated later in Figure 10).

The concept of communities of practice (Wenger, 1998) has influenced our initiative (Yukawa, Suthers \& Harada, in preparation). Since its introduction by Lave and Wenger in 1991 and its elaboration by Wenger (1998), the concept of communities of practice (CoP) has become widely known as a social theory and a learning theory. According to Wenger (1998), three characteristics distinguish CoPs from other types of communities: CoPs have a community, a domain, and a practice. The community is a group of people who interact regularly and share common practices with respect to a domain.

Although ideally all participants in a reform effort will function as one community, our experience in HNLC is that multiple communities of practice are involved at the outset, and continue to be relevant as the work progresses. The subject of our systemic reform effort - the state school system - is not a unitary community of practice. The most salient distinction we encountered is between "the state" and "the schools." "The state" is the statewide administrative system in Honolulu, which includes ATR among many other state offices. "The schools" are the teachers, principals and other support personnel who work together within schools geographically distributed across the islands. Our reform effort includes a third community of practice, researchers and their students in our university laboratory (LILT), forming a tripartite relationship. 


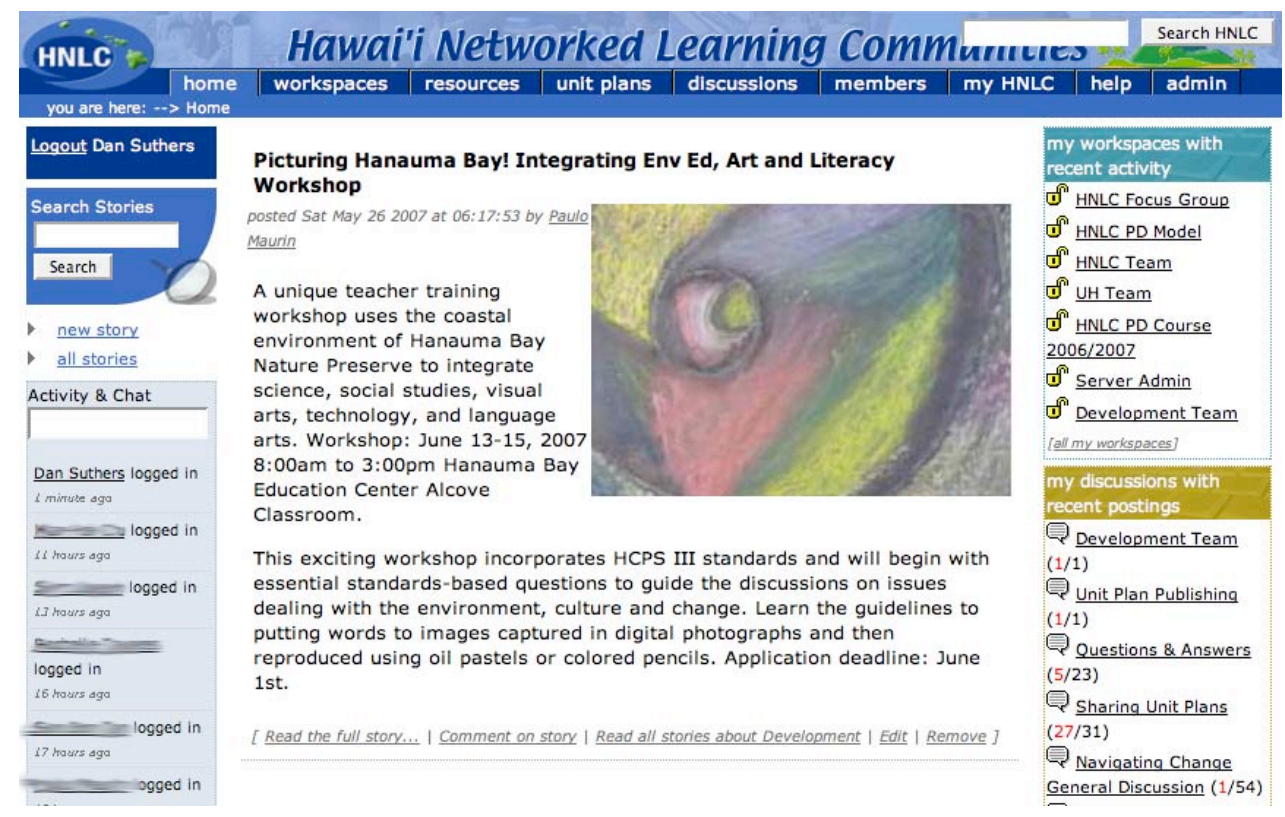

Figure 1. The virtual community center (hnlc.org) home page, May 2002 version

The individuals doing the work of HNLC do so within the context of their professional communities and in the course of performance of their job duties in their organizations. The functioning of the entity formed by the partnership of these three communities of practice is influenced by the orientation of each community's practice, its resources, and its constraints. Therefore, an analysis that examines the partner communities is appropriate, and conceptual tools are needed to understand each partner community in relation to the others.

\subsection{Theoretical Foundations}

This paper illustrates how activity theory provides a useful framework within which to understand the relationships between partner communities. Cultural-historical activity theory, as it is now called, originated in the late 1920's in the confluence of developments in Russian psychology. Vygotsky (1978/1930), seeking an account of the relationship between culture and mind, recognized that cultural artifacts mediate human action (Vygotsky, 1978/1930). Concurrently, Basov proposed that "human activity, understood as an interaction of an organism with environment ... be discerned as a special object of analysis" (Kaptelinin \& Nardi, 2006, p. 174). Activity theory was then more fully developed by Vygotsky's student Leontiev (1978), who sought a historical account of mind, and analyzed activity at the levels of motivated activity, goal-oriented actions, and routine operations (Kaptelinin \& Nardi, 2006; this paper addresses the level of motivated activity). Cultural-historical activity theory has developed into a sophisticated theoretical framework that encompasses a diversity of research programs. Here we summarize only those aspects relevant to the present paper: for further reading see Wertsch, Del Rio \& Alvarez (1995), Engeström Miettinen \& Punamäki (1999), and Kaptelinin \& Nardi (2006). 


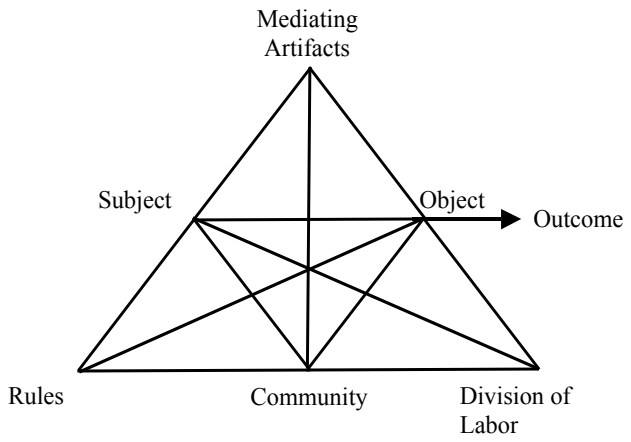

Figure 2. A generic activity structure

Cole and Engeström elaborated activity theory with conceptual tools to understand cultural-historical resources for and constraints on collective action and organizational change (Cole \& Engeström, 1993; Engeström, 2001). Cole and Engestrom's (1993) widely used framework is shown in Figure 2. This framework may be understood briefly as follows: The activity of any subject is directed towards an object in order to achieve some outcome. Kaptelinin and Nardi (2006) discuss the distinction between the Russian objekt, the material object on which one acts, and predmet, the mental objective or envisioned transformation of the object that Engeström calls the "outcome." An objective may be accomplished by acting on the object directly (as it is in most animals as well as ourselves), or may be mediated by culture and its artifacts, as Vygotsky proposed. The apex vertex, "mediating artifacts," includes tools in the broadest sense, including language and other conceptual tools as well as physical devices. Cole and Engeström proposed that the subject's relationship to the object is also mediated by our participation in a community.

Mediation is a key concept, and can be applied analytically between any three elements of the activity system (the triangles of the figure). For example, the subject's relationship to a community is mediated by rules of participation; the community's relationship to the object is mediated by roles (division of labor) that define forms of participation oriented towards the object; and the subject may be enabled to enact his or her role by artifacts that aid aspects of this practice. The configuration of an activity system is dynamic and constantly changing. Problematic issues and potential for change can be understood in terms of contradictions and tensions between elements of the activity system. More recently, Engeström developed a "third generation" of activity theory in which two interacting activity systems are taken as the minimum unit of analysis in order to understand inter-organizational learning or "expansive learning" (Engeström, 2001). This third-generation approach is taken in this paper.

Like Barab, Schatz and Scheckler (2004), we found that although activity theory is useful, multiple analytic models are needed. Activity theory provides a structural model within which tensions are to be identified, but additional guidance is needed to analyze these tensions. Our analysis incorporates the dualities of Wenger's (1998) communities of practice (CoP) model. A duality is not a binary variable, nor a spectrum along which a system has some value. Both elements of the duality are always present and interact both problematically and productively. Wenger (1998) identifies four dualities that address "the fundamental issues of meaning, time, space, and power," namely: (1) participation and reification, (2) the designed and the emergent, (3) the local and the global, and (4) identification and negotiability. While Wenger uses the concept of dualities to examine 
the forces that create and sustain CoPs, we apply this concept to understand forces between as well as within communities. We will also adopt Wenger's (1998) three modes of belonging, as follows: engagement (direct interaction between participants in negotiating shared meanings and practices), imagination (conceptualizations that transcend immediate experience to form connections across time and space), and alignment (coordinating activities to fit within broader structures and enterprises).

\section{Method}

The account presented in this paper initially became apparent through an attempt to make sense of the lived experience of managing the project by applying concepts from activity theory and communities of practice theory, which we were studying concurrently. This account was not derived through a process of inductive generalization, nor was it subjected to a positivist program of hypothesis testing. Rather, it was derived through a dialectic between experience, theorizing, and examination of our historical records, and through conversations between the authors in which we checked and, where necessary, challenged our interpretations. In preparing this paper, we identified the empirical claims being made and searched our records for evidence or counter-evidence relative to these claims. This process carries the risk of bias, but it enables us to handle the diversity and quantity of experience on which we draw. In order to provide the reader with a basis for evaluating our claims, we footnote empirical claims throughout this paper with examples of and reference to the documentation on which we base the claim.

\subsection{Sources of Data}

Our records include meeting notes; surveys, interviews, and focus groups; email and other communications; teachers' online reflection logs and unit plans; and documents resulting from our joint effort such as professional development session agendas and resources, strategic plans and reports. The meeting notes include all meetings of the UH LILT team, meetings between UH and ATR attended by the authors, school visits, and focus groups. The first author has taken comprehensive notes during project meetings since 1999, and project staff who conducted training during school visits provided their notes. The online discussions include hundreds of messages posted by teachers in response to prompts to reflect on their work and their engagement in the professional development program. Project documents include strategic planning documents created jointly by project directors and other staff early in the project and documents created by ATR during their planning of professional development sessions. Surveys conducted in 2003 and 2007 provide snapshots of teachers' attitudes, and interviews conducted 20052007 provide ATR and LILT staff reflections.

\subsection{Grounding the Claims}

A list of the empirical claims underlying the account was compiled, and distributed among authors. We searched our data records for instances that would corroborate or contradict each of these claims, following a triangulation strategy. Suthers examined meeting notes and focus groups dating back to 1999, project documents, and survey results; Harada read over 1200 messages posted online by teachers and ATR facilitators; and Yukawa reviewed email and notes on interviews she conducted. Evidence relevant to the claims was compiled in a shared wiki page and used to generate the footnotes in this 
paper. When contradicting evidence was found, the theoretical account was revised accordingly.

\section{Three Communities, Three Activity Systems}

This section characterizes the three major groups of participants in our systemic reform effort. Their activity systems will be described individually before we examine relationships between them that seek either drive or impede change.

\subsection{Teachers}

The object of school reform is to change the practices of teachers and the activity systems within which they are embedded to better support gains in student achievement. Therefore it is appropriate to begin with the teacher community of practice and describe their activity system (Figure 3). Teachers act as members of a school community. Students are the object of their activity and student learning the outcome being sought. ${ }^{2}$ The primary artifacts that mediate teachers' student-oriented activity include curricular resources such as unit and lesson plans, instructional media, and technologies.

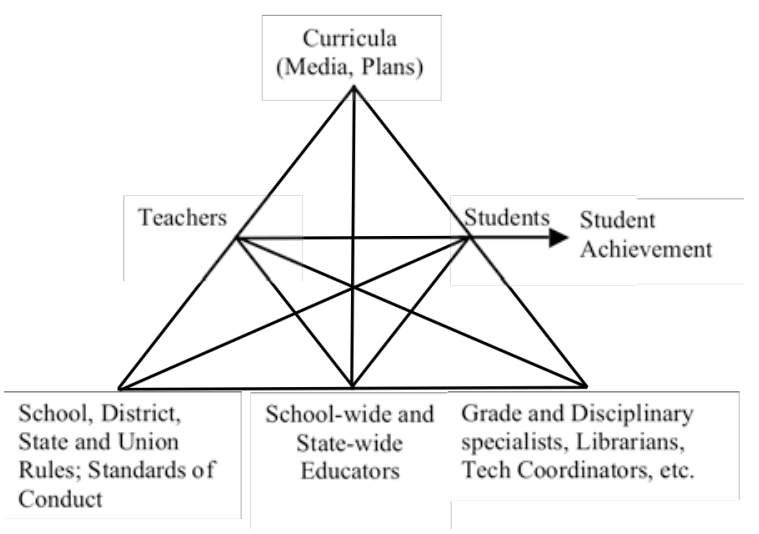

Figure 3. Activity system for teachers in school teams

Teachers are members of communities at several granularities, including a school community and a statewide community of teachers, represented by their union. ${ }^{3}$ These communities along with others form a larger entity, the public education school system known as the Hawai'i Department of Education, but in this analysis we focus on the community comprised of teachers themselves. Rules that regulate teachers' activity include state system regulations, guidelines for standards-based education and licensing

\footnotetext{
${ }^{2}$ In addition to the fact that this is their job duty, examples of direct evidence include the following. At a teacher focus group April 19, 2003 attendees were asked to comment on hnlc.org software tools that were designed for them. A teacher commented, "This could be useful for my students." When asked to discuss ideas for new tools that could be developed as part of the hnlc.org website (which we have consistently presented as a site for teachers), without exception the suggestions made were for tools that would be of use to their students, and not for tools that would directly support their own professional development or professional activities.

${ }^{3} \mathrm{http}: / /$ www.hsta.org/
} 
procedures. ${ }^{4}$ Division of labor is accomplished through specialization such as grade level specialization at the elementary level and disciplinary specialization at higher grades. The school community includes other roles such as principal, librarian, technology specialist, or resource teacher. ${ }^{5}$ Schools were required to form a leadership team for participation in HNLC reflecting these roles. ${ }^{6}$

According to our survey and focus group data, tensions within the teachers' activity system that affect the systemic initiative include resource limitations of all typeslimited technological resources, ${ }^{7}$ lack of technical knowledge, ${ }^{8}$ inexperience with collaborative technologies, ${ }^{9}$ and insufficient resources ${ }^{10}$ and time $^{11}$ for professional

\footnotetext{
${ }^{4}$ See for example http://doe.k12.hi.us/schooloffice/humanresources.htm (state regulations) http://doe.k12.hi.us/standards/index.htm and http://reportcard.k12.hi.us/ (standards-based education) and http://www.htsb.org/ (teacher licensing).

${ }_{5}^{5}$ This division of labor is ubiquitous throughout the United States. http://doe.k12.hi.us/personnel/index.htm lists some categories.

${ }^{6}$ For example, the Cohort II (2003-2004) Letter of Commitment states: "School agrees to establish a school leadership team that consists of the following individuals: an administrator, a teacher partner, and two additional teachers and/or support staff personnel (e.g., technology coordinator, librarian). While the composition of the team is left to the respective school, the team must reflect collective expertise in science, mathematics and technology." Of the 47 respondents to a survey of HNLC teachers in $2003,40.4 \%$ identified their primary role as classroom teachers, $6.4 \%$ as HNLC teacher partners (half-time positions funded by HNLC), $10.6 \%$ as technology coordinators for their schools, $6.4 \%$ as library media specialists, $19.1 \%$ as administrators, and $17 \%$ as "other," including standards implementation design coordinator, resource teacher, special education resource teacher, retired, lab technician, curriculum coordinator, and staff development coordinator. These were experienced educators: $76 \%$ of respondents had 10 or more years of experience and $65 \%$ had 10 or more years in Hawai ${ }^{1}$. (Figures are from Doane, 2003).

${ }^{7}$ The needs assessment conducted at the outset of this project in 1999-200 concluded, "Use of technology is weak or nonexistent in science and math instruction, and occasional at best for access to outside resources, professional development, or mentoring" (from final report, NSF Grant \# 9907894 ). This conclusion was corroborated by teachers' expressed needs during the grant period. For example, the HNLC 2003 focus group identified availability of computers as a problem: "lack in classroom; all in lab" and "NSF [this grant] assumes that schools already have computers in place, but this isn't a given in rural schools." The HNLC 2006-2007 teacher survey indicated that technology access is an ongoing problem ("We desperately need a mobile lab with computers") although teachers' awareness of the diversity of technology available was raised by HNLC: "We did not have enough tools (cameras, laptops, digiscopes) to implement technology as much as we wanted to." The funding agency did not permit HNLC to use grant funds to address this problem systemically, except as needed to support our program of professional development.

${ }^{8}$ HNLC 2003 teacher focus group identified "Lack of high quality talent on island" as a limiting factor. Notes from a visit to a school on a rural island in 2005: "[Teacher] tried to kidnap [ICS Graduate Student] to get technical support for [school]. Apparently the tech person at [school] is now the reading support person, and doesn't have time, or perhaps the skills, to help the [school] teachers transfer their html pages." HNLC 20062007 teacher survey: "I am hesitant to use a computer for activities other than word processing. I need a step-by step approach to be able to figure out how to use a computer." However, at this point in the project there is also evidence that HNLC has been responsible for closing the technical gap. For example, a journal entry from 2007 reads: "I have become so involved with the technological part of HNLC that I am learning to try new things with my computer. I have my computer, camera, and the elmo to demonstrate things in my teaching. I am not afraid of using these technologies when showing the students data or collecting data." In a 2007 interview, a resource teacher stated, "Some of our teachers are at such a low technology skill level that putting them in this environment [hnlc.org], besides the goals of trying to get them to network, helps them become more confident at using their computers other than for typing. ... Their level is very low. It helps to have it part of our PD courses, forcing them to come into this world."

${ }^{9}$ For example, although $87 \%$ of respondents to a 2003 survey reported regular use of email, over $50 \%$ reported never having used online discussion boards for professional development while over $85 \%$ reported never having used online chat rooms or instant messaging for professional development.

${ }^{10}$ For example, in a 2003 survey, $49 \%$ of respondents disagreed and $17 \%$ strongly disagreed with the statement "I believe that I can get the professional development support I need completely from within my school" (Doane, 2003). In a focus group held in 2004, teachers requested the ability to email DOE resource people to answer questions on standards saying, "Standards confuse us, we need to know what the people who put them together are thinking."
} 
development activities, constrained by the need to hire substitute teachers. (There is limited time to plan for even the daily demands of the classroom.) During the course of our project, the state content and performance standards were revised twice, ${ }^{12}$ creating added challenges for teachers endeavoring to organize their curriculum plans by the standards. ${ }^{13}$ The threat of sanctions mandated by the federal "No Child Left Behind" (NCLB) legislation can result in de-prioritization of all activities-including implementation of the place-based inquiry learning advocated by HNLC - other than preparation for standardized tests. ${ }^{14}$

\subsection{State Department of Education Colleagues}

Our systemic reform effort is undertaken in collaboration with the state-level Department of Education (DOE). ${ }^{15}$ We collaborate most closely with the Advanced Technologies Research (ATR) group, ${ }^{16}$ one of two parts of Advanced Technologies Research Branch (ATRB), and we also work with staff from other offices responsible for assessment, curriculum standards and resources, and higher-level administration. ${ }^{17}$ Since our

\footnotetext{
${ }^{11}$ For example, from the 2006-2007 teacher survey: "Time is always a factor. Though the HNLC project was meant to help with the HSA [Hawai'i State Assessment] and implementing standards, there is only so much time in the day to complete all that is required in the classroom."

${ }^{12}$ When the project began, implementation of the Hawai' i Content and Performance Standards (HCPS) had also just begun. Subsequently, they were revised to HCPS II and III (http://doe.k12.hi.us/standards/index.htm). However, perhaps because HNLC's support focused consistently on standards, teachers' responses to the 20062007 survey indicate progress: "HCPS III and assessment were very critical pieces that allowed us to ask questions and construct our team plan." "I have been more successful integrating a variety of standards and benchmarks into my unit plans due to the time we spent on this."

${ }^{13}$ At the 2007 Learning Fair, teachers said that some changes from HCPS II to III were worrisome because they required schools to alter their curriculum emphases ("we now have to move this from first quarter to third quarter" or "now we have to teach this at grade 4 and not grade 3 "). In some cases, the new math textbooks the schools had just purchased "did not match HCPS III." Teachers widely mourn the removal of the "Malama I Ka 'Aina" (caring for the land) standard on which many curricular units have been based.

${ }^{14}$ For example, a teacher commented during the 2003 focus group "In Algebra I and II, HCPS drives what has to be covered: 13 chapters; students must be able to do problems in all of them. So we can't take a week out for a project." Journal entries in 2007 state "Being in restructuring hindered my science lessons. There is so much focus on math and reading that it felt like the other subjects were getting pushed out of the way"; and "To be very honest, I had become very tied-down by the curriculum calendars, testing, and other demands of NCLB. I found myself, like many others, chasing and trying to keep up with our language arts and math lessons." Part of the value of HNLC is to counter these trends. The previous teacher continues: "By participating in HNLC this year, I made an effort to get back to the kind of teaching I was exposed to. The result was a tremendous amount of hands-on learning. Students said: Science is fun, Mrs. I, what are we going to study next?" Implementation of high-stakes science assessments is beginning in Hawai' $i$, and HNLC teachers may be ahead of the game: "... the Hawaii State Assessment is a major part of my teaching plans. In order to prepare the students for the science component of the HSA, the teachers are starting to incorporate inquiry lessons beginning in kindergarten. We are making students proficient in these skills." In a 2005 interview, an ATR resource teacher stated, "In developing the training sessions, we needed to do more research in the area of school level tasks, or the kinds of compliance initiatives on their plate, and seeing how we could help them ... but for the short term, they needed to raise reading and math scores."

${ }^{15} \mathrm{http}: / /$ doe.k12.hi.us/index.html

${ }^{16} \mathrm{http}: / /$ atrb.k12.hi.us/. For example, during 2006 the first author attended at least 19 meetings involving ATRB staff, not counting major events such as the annual conference and two annual teacher meetings. Many other meetings not involving the authors of this paper took place between project staff.

${ }^{17}$ A state science curriculum specialist was a co-principal investigator (PI) on the planning grant, and participated in early planning meetings. A state mathematics curriculum specialist also participated in the initial years of professional development. These collaborations did not continue after the individuals left their jobs. An assistant superintendent collaborated substantially in the grant planning and early implementation phases. Our ATR co-PI met regularly with the assistant superintendent (her supervisor) during the entire duration of the project.
} 
interventions, including mentoring and technology, are undertaken in collaboration with ATR, we will describe the activity system for that sub-community within the DOE.

ATR team members who are tasked with HNLC responsibilities direct their activity (Figure 4) towards teachers as their object ${ }^{18}$ and seek change in practice, particularly with respect to the use of technology and standards implementation. As ATR's engagement in HNLC deepened, ATR staff sought the implementation of assessment-driven, standardsbased curricula through activities that engage student interest and participation, in particular, place-based inquiry learning leveraging the environmental, economic, and cultural context and concerns of students. ${ }^{19}$ ATR team members seek to achieve this outcome through professional development (PD). The mediating artifacts include plans for PD sessions and the incorporation of available PD materials. ${ }^{20}$

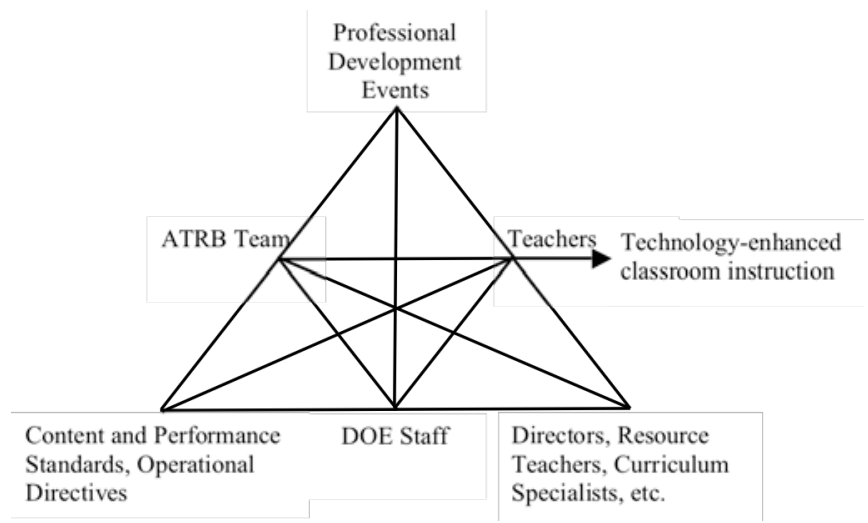

Figure 4. Activity system for our ATR colleagues

\footnotetext{
18 "The Advanced Technology Research Branch (ATRB) of the Hawai i Department of Education, is responsible for exploring and researching new technologies which support and improve classroom instruction." (http://atrb.k12.hi.us/about_us) and "Advanced Technology Research focuses on the integration of technology through: Online courses for students and teachers; Database development to support standards-based teaching and learning. We also provide various face-to-face training on various software applications and curriculum integration." (http://atrb.k12.hi.us/atr page). Although ATR includes student programs

(http://atrb.k12.hi.us/atr_page/student-programs), a major activity of ATR staff is to offer teacher professional development programs (http://atrb.k12.hi.us/atr_page/teacher-programs). Since the HNLC initiative focused on teacher professional development, we analyze ATR with respect to the latter activity.

${ }^{19}$ ATR's Training Services (http://atrb.k12.hi.us/training-services) focuses on technological skills such as the use of office tools, multimedia, databases and data gathering. A teacher at the 2005 focus group commented on ATR: "They really are experts at PowerPoint, but need to make the connection to classroom practice. No one should be out of classroom more than three years." However, ATR staff preparing HNLC Professional Development plans for 2005-2006 identified the following intended outcomes: "Transform science and math content standards into benchmarks that are measurable learning objectives. Devise criteria and tools for assessing achievement of these benchmarks. Incorporate an inquiry process in classroom projects and units. Build inquiry around environmental, place-based learning that fosters stewardship of natural resources within our communities. Integrate the use of technology tools for information and learning. Involve community groups and individuals as mentors and resources." See also footnote 27.

${ }^{20}$ ATR meetings we attended frequently focused on scrutiny and editing of syllabi and agendas for upcoming professional development sessions. ATR staff also incorporated materials such as curriculum reform strategies that have been proposed by national reform leaders such as Tony Wagner (Making the Grade) and Grant Wiggins and Jay McTighe (Understanding by Design) and were being promoted by the DOE administration.
} 
The ATR activity system exists within a community of DOE state-level staff. ${ }^{21}$ The division of labor within ATR and the other staff engaged in HNLC includes the ATR director (also co-Principal Investigator on HNLC), a project director, resource teachers who are charged with planning and executing most PD activities, and curriculum specialists and others who are asked to support the effort. ${ }^{22}$ Their activities are regulated by the content and performance standards ${ }^{23}$ and by directives from the superintendent's office and Board of Education. ${ }^{24}$

Contradictions and tensions within this activity system affect success at reform efforts. Revisions to the content and performance standards created discrepancies between educational materials produced in previous years of the professional development program and new materials designed to work with the revised standards. ${ }^{25}$ Budgetary and political pressures result in operational directives that change priorities and constraints (e.g., limiting travel for school visits) ${ }^{26}$ or mandate new foci and methods (e.g., curriculum mapping or creating learning communities). ${ }^{27}$ Resource teachers hired for HNLC were inexperienced in the kinds of practices being promoted. ${ }^{28}$ Due to their workload, they had limited time to reflect, and were sometimes forced to develop their program and materials as little as a few days before the scheduled professional development events in which they are to be used. ${ }^{29}$

\footnotetext{
21 "ATRB is a section under the Office of Curriculum, Instruction and Student Support (OCISS)" (http://atrb.k12.hi.us/about_us). ATRB is physically housed with other OCISS offices in a single building in a suburb of Honolulu that is isolated from other State offices in downtown Honolulu and on a different island from most of the schools involved in this initiative. Teachers often refer to offices and staff in these offices collectively as "the state".

${ }^{22}$ As documented in annual project reports to the National Science Foundation, and evidenced by the presence of these persons at HNLC meetings.

${ }^{23}$ As in most school districts in the United States, the impact of the state standards is ubiquitous throughout HDOE. See http://doe.k12.hi.us/standards/index.htm. Evidence of the impact of standards on HNLC ATR staff planning may be found, for example, in the session agendas for the 2006-2007 professional development program. These documents identify the specific outcomes for each session and the activities and tasks employed to achieve the outcomes. They clearly focus on assessment-driven, standards-based curricula ${ }^{24}$ When the General Learner Outcomes (GLO, http://doe.k12.hi.us/standards/GLO rubric.htm) were announced, HNLC plans were revised to incorporate them. Similarly, the 2005 Annual Report to NSF, p. 7 , mentions alignment of HNLC with the HDOE Vision of the High School Graduate and also mentions that revised project internal evaluation and review instrumentation were aligned with HDOE objectives. In 2003, the assistant superintendent announced a partnership with a scientific project, All Species Hawai' $i$, at an HNLC board meeting, leading to a deliberate effort to get teachers to align their unit plans with this project.

${ }^{25}$ For example, meeting notes throughout 2005 show this concern surfacing repeatedly for the transition from HCPS II to HCPS III. It was necessary to train teachers on the new standards, but the web site still represented their unit plans with the old standards, leading to questions concerning who should translate their unit plans. ${ }^{26}$ In 2003, the assistant superintendent requested that branch directors reduce unnecessary travel: this led to reduction in school visits and attempts to rely more on videoconferencing and online communications.

${ }^{27}$ ATR resource teacher interview October 2005: "The content [of the PD program] evolved from us wanting to support their efforts in standards-based education and assessment, to develop curriculum in a certain way. We also realized that a key point of the grant was inquiry and place based learning. We were trying to address all those goals and pull the pieces together. I don't know if it was constant because state initiatives, like curriculum mapping, came into the picture."

${ }^{28}$ ATR resource teacher interview October 2005: "We were learning this program and applying it at the same time in the PD. It was rich, meaningful learning for us. We were learning and using the teachers as our students, while having them learn and use it with their students ... that's why we were all stressed out. The teachers had a lot of questions that we couldn't answer because we were learning along the way".

${ }^{29}$ The joint planning meeting for a session to be conducted at multiple schools beginning January 27, 2005 was held on January $21^{\text {st }}$. This was an improvement over prior planning in which LILT was informed of our allocated time slot or technology support expectations a few days in advance.
} 


\subsection{University of Hawai i Researchers}

The University of Hawai' $\mathrm{i}(\mathrm{UH})$ team, the other partner in funding and implementing the systemic reform project, consists of members of the Laboratory for Interactive Learning Technologies (LILT) in the Department of Information and Computer Sciences (ICS). We first examine LILT team members' activity in the context of a community of researchers. The object of LILT's work is technology mediation of learning in the context of collaboration and communities, or as abbreviated in Figure 5, collaborative technologies ${ }^{30}$ of which hnlc.org is an example. Our activity is directed towards this object to achieve research findings and publications as an outcome. ${ }^{31}$ In this endeavor, we participate in a community of researchers in our institution and extending to international communities identified as Computer Supported Collaborative Learning, Education and the Learning Sciences, and Library and Information Science. ${ }^{32}$ Our team follows the standard academic role specializations of faculty, full time researchers, and graduate students (who themselves specialize in roles such as interface designers, system programmers, and community managers). ${ }^{33}$

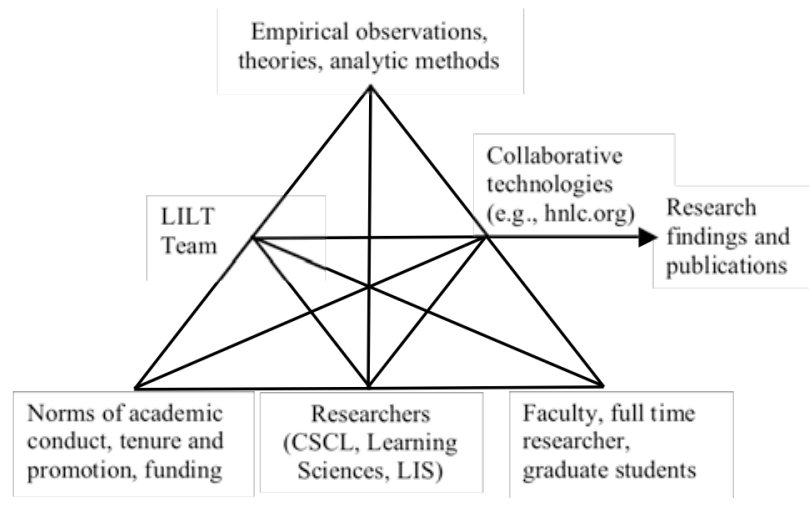

Figure 5. Activity system for participating university researchers

The university team's activity system includes tensions and constraints familiar to many readers of this paper: the competing priorities of research, teaching or class work, and (for faculty) administrative and service activities.

\subsection{Beyond an Additive Model of Partnerships}

The foregoing characterizations of the activity systems of the three partners involved in HNLC are offered as the basis for an analysis of how the relationships between these activity systems explain the issues we experienced in our collective efforts towards instructional change and can inform future efforts. A simple approach to such an analysis

\footnotetext{
30 "Currently LILT has a strong focus on studying how technology affordances support social processes of learning, ranging from the meaning-making dialogues of small groups to supporting reflective practice in online communities." (http://lilt.ics.hawaii.edu/lilt/)

${ }^{31} \mathrm{http}: / /$ iltt.ics.hawaii.edu/lilt/research/pubs.html

${ }^{32}$ The first author and his students affiliate primarily with CSCL and the Learning Sciences. The second and third authors affiliate with Library and Information Science, and the third additionally with Education.

${ }^{33}$ During much of this work, the LILT team consisted of two faculty, one full time researcher, and several graduate students in computer science and library science (http://ilt.ics.hawaii.edu/lilt/team/index.html)
} 
would be to identify similarities and differences between the systems, and identify what each partner contributes as well as potential problems. For example, teachers' primary activity is oriented towards students with the aid of curricular resources as cultural tools (Figure 3); ATR staff's primary activity is oriented towards teachers with tools for training and professional development sessions (Figure 4); and LILT researchers' primary activity is oriented towards technology with research theories and methods as their tools (Figure 5). These differences are to be expected and indeed are the very reason for the partnership, as each brings something unique to the partnership. Yet partners need to be aware of their differences in orientation (e.g., motivations and goals) and tools (including language) to prevent misunderstandings.

However, a reform effort involving partners from three distinct communities of practice cannot be fully understood by considering only the union of their contributions under a division of labor model (e.g., in which LILT is responsible for technology and ATRB is responsible for professional development). More complex relationships-pair wise and tripartite in this case-must be considered to understand challenges and potential for change. Following expansive learning theory, which "takes two interacting activity systems as its minimal unit of analysis, inviting us to focus research efforts on the challenges and possibilities of inter-organizational learning" (Engeström, 2001), we began to examine the HNLC partnership as interacting activity systems. A multi-system analysis is particularly important in understanding the role of technology in school reform, where one partner introduces tools that are intended to mediate and transform the activity of the other two. Below we will use the characterizations of the three activity systems to support analysis of inter-system relationships, an analysis that reveals how further advantages of a partnership are realized in transformations to each of the partners that occur through the interactions between them.

\section{Transformations of Partners}

In the remainder of this paper, we present inter-system relationships of increasing complexity, beginning in this section with examinations of how individual partners may be transformed by participation in HNLC, and working up to bipartite and tripartite relationships in the next two sections. Much of this discussion will build upon the following activity-system account of a key concept in school reform.

\subsection{An Activity-System Account of Reflective Practice}

The object of school reform is to transform existing practice in a sustainable manner. In order to effect and sustain this transformation, practice itself must include ongoing reflection on practice that is directed towards the transformation (Schön, 1983; YorkBarr et al., 2001). An activity schema for reflective practice developed by the first author is shown in Figure 6. Practitioners (the Subject) are engaged in a primary practice indicated by the lower activity system (P), in which they act on some Object directly and with cultural tools (Tool-1) to achieve some outcome (Outcome-1). In the reflective activity (R), the mediating tools of the practice (Tool-1) become the objects of reflection, possibly resulting in criticism and revision of the tool or other innovations. Other aspects of the activity, such as rules and division of labor, may also be reflected upon and revised; these aspects of reflection are omitted from the figure for simplicity. A meta-tool is employed as the tool by which reflective consideration of the primary tool is accomplished. For example, the meta-tool can be theory, professional development 
materials and activities, and/or discourse within a community. Tool-1 of the primary activity system is deliberately revised into a new one, Tool-2, in order to improve outcomes. As a result, the primary activity system is transformed into a new activity system (P') using Tool-2 with different (hopefully improved) outcomes (Outcome-2). The process repeats with this transformed activity system, resulting in a series (as it were) of transformed practices $\mathrm{P}^{\prime} \Rightarrow \mathrm{P}^{\prime}{ }^{\prime} \Rightarrow \mathrm{P}{ }^{\prime}$ ' etc. Reflective practitioners must simultaneously or periodically maintain a reflective activity $(\mathrm{R})$ in order to continuously transform practice in the primary activity $(\mathrm{P})$.

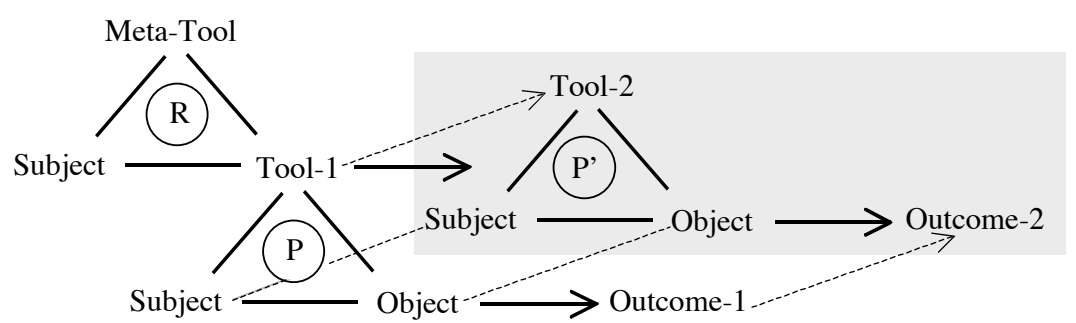

Figure 6. In reflective practice, the tools for the current practice $(\mathrm{P})$ become the object of reflection $(\mathrm{R})$ leading to a revised practice $\left(\mathrm{P}^{\prime}\right)$

For example, the ATR and LILT teams want to help teachers to reflect on their instructional resources and unit and lesson plans and on how these tools are implemented in the classroom towards the objective of improving student achievement. ${ }^{34}$ In terms of Figure 6, teachers are the Subject, students the Object, curricular resources and plans are the Tool (Tool-1 at time 1), and student learning the Outcome. When they engage in reflective practice, teachers' curricular resources and instructional plans become the objects of inquiry in a second, parallel activity system. Some implications of this attempted transformation of teachers' practice will be discussed in section 6.2.

\subsection{Reorientation Towards Other Activity Systems}

Although we have described the activity systems of each partner community as they were constituted at the initiation of HNLC, participation in a partnership changes the very orientation of these systems from the outset. We are best able to document the change in our own orientation. Figure 5 is accurate from the standpoint of LILT's functioning as a research team in general, but does not capture an important transformation of LILT's object directness that resulted from our participation in HNLC. Initially, the design of hnlc.org was our primary object, as would be expected of a research group situated in a computer science department and as shown in Figure 5. However, as LILT's engagement in HNLC deepened, LILT also became oriented towards educators (school team and ATR members) as our objects. In this orientation, hnlc.org as a technology plays a mediational role, as tool rather than object (Figure 7). LILT seeks to use hnlc.org as a means of supporting teachers' reflective practice in a community of practice, ${ }^{35}$ and as a means of ATR's mentorship of that reflective practice. ${ }^{36}$

\footnotetext{
${ }^{34}$ These objectives are stated in the project summary page of the proposal submitted by ATR and LILT PIs to NSF. This alignment continued as LILT members frequently collaborated with ATR in the refinement of planning documents for professional development mentioned in footnote 20 .

${ }_{35}$ Although the authors were previously aware of Wenger's work, meeting notes and laboratory wikis show that the concept of Communities of Practice (CoP) was first discussed explicitly by the LILT team in October 2003.
} 


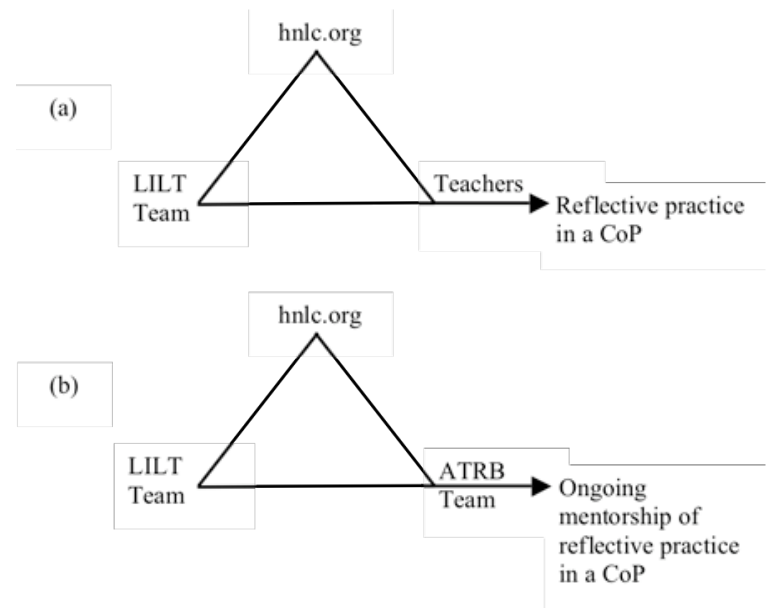

Figure 7. LILT's activity as oriented towards HNLC partners

In the process, our own professional identity was transformed. Team members came to care deeply about the extent to which we were providing value to educators in both the ATR and school communities. ${ }^{37}$ Success no longer consisted solely of academic research focused on technology: a sense of accomplishment was also felt when members of the target communities reported realizing the value of the technologies we provided. ${ }^{38}$

Subsequently, LILT PIs began to express their model of professional development as one of ongoing participation in a community of practice. By early 2004, the ATR-based project director was working actively with LILT team members to plan an online professional development course that included CoP as an explicit concept. However, after this project director left HNLC in mid-2004, implementation of professional development as ongoing participation in a community lapsed until joint ATR/LILT planning began for the 2005-2006 professional development program.. In October 2005, the present authors began analyzing HNLC as a partnership between communities of practice (authors' email records), and writing a paper currently under revision.

${ }^{36}$ In March 2004, a joint ATR-LILT meeting was held to plan ATR's use of hnlc.org to mentor teachers on matters including technology use and unit planning. The second author was assigned to facilitate ATR's telementoring. Meeting notes and email records show regular discussion of mentoring in LILT and joint meetings for the next two years, during which LILT PIs repeatedly encouraged ATR staff to utilize hnlc.org to support meaningful ongoing professional development activities between the face-to-face sessions. (Previously, ATR staff used hnlc.org primarily as a place for teachers to post responses to prompt during PD sessions, or a place to post noninteractive responses to assignments.).

${ }^{37}$ By the 2006-2007 PD season, two graduate students were working directly with ATR resource teachers in planning PD. The passionate involvement of one student was evidenced by his regularly seeking advice from PIs, his emotional response when teachers did not receive the technology well, and the warm thanks that teachers subsequently gave him on several occasions for his efforts. This concern was not limited to students tasked with working directly with teachers. During the 2004-2005 PD season, all LILT team members were sent on school visits in a deliberate move to create a more direct connection between developers and teachers. As a result, students who were hired (and viewed themselves) primarily as programmers became engaged in figuring out what teachers wanted, and began advocating for the teachers' point of view in project meetings. ${ }^{38}$ From an interview of a graduate research assistant, June 2007: "This year, we've been putting in extra time to support the teachers and RTs [resource teachers] and trying to do this as quick as possible. [One graduate student] even takes late evening calls from [one RT]. For developers, it's the first year that we've had any use, except for the forced use at face-to-face sessions [in previous years]. We've received more feedback on usability issues, and impressions, seeing the [teachers' reflection] logs. This is great. It makes it easier to see what you should deal with, in the organization of information. We've had had some really amazing teachers involved on so many levels. Before, people didn't get a clear idea and clear instructions of what to do, even if they were willing to do things. This year, on their own initiative they're shooting out in all directions." 
However, the pre-existing activity was not replaced: academic expectations to experiment with technology innovations and to publish papers remained strong. The simultaneous presence of two major activities led to tensions in LILT, because the need to innovate conflicted with both the need to provide educators with a stable, simple environment and the time commitment involved in supporting a large user base. ${ }^{39}$ But the simultaneous presence of two major activities also led to an important transformation that can be understood in terms of the schema for reflective practice introduced previously.

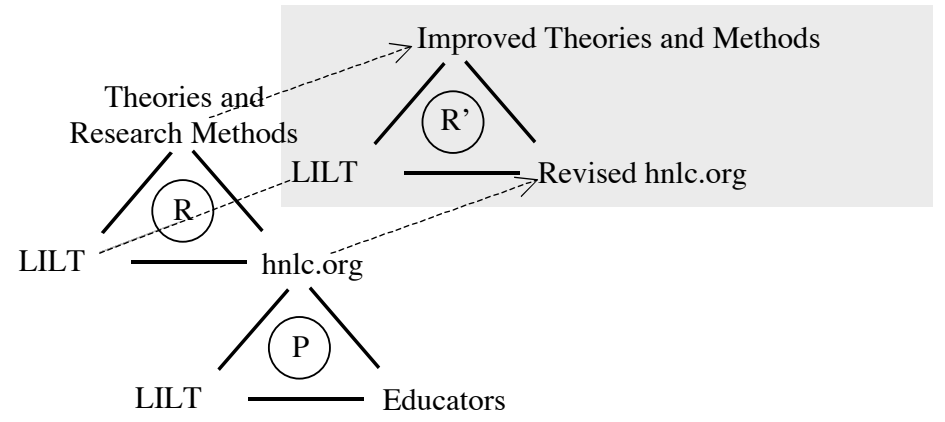

Figure 8. Reorientation of LILT from research $(\mathrm{R})$ to the practical concerns of educators $(\mathrm{P})$ sifts the role of hnlc.org from object to tool, providing grounded experience that in turn drives change in the reflective system (R').

As shown in Figure 8, LILT's reorientation towards educators resulted in a conversion of hnlc.org from subject of the research-oriented system (R) into tool of the applied practice-oriented system $(\mathrm{P})$. This is the opposite of the tool-to-subject conversion of the account of reflective practice we have just given. However, this reversal does not mean that LILT became less reflective. To the contrary, given that both systems $(\mathrm{R})$ and $(\mathrm{P})$ remain active, ${ }^{40}$ the transformation was from a primarily reflective but inwardly focused academic system to one that also included a strong practice component that provided the empirical basis that drove changes in the reflective component. ${ }^{41}$ In Wenger's (1998) terms, the transformation can be seen as a shift in forms of participation from imagination of potential users of the technology to engagement and alignment with users of the technology. Thus, although a simplistic view of a reform partnership is that one entity seeks to transform another, we now understand that the transformer is itself transformed by the very effort to transform the other.

\section{Alignments and Tensions Between Activity Systems}

We have discussed transformations within activity systems that are sought by reformers (reflective practice) and that are consequent of the reorientation of one activity system to another (engagement and alignment). We now turn to alignments and tensions between

\footnotetext{
${ }^{39}$ The first author's ideas for innovations were regularly deferred in favor of repairs of problems that were impeding teachers' use of the site, implementation of new features needed for upcoming PD sessions, and in reimplementations of the entire code base intended to make these ongoing changes easier.

${ }^{40}$ This simultaneous activity was reflected in the specialization of LILT meetings, including practice-oriented meetings focusing on our coordination with ATR and meeting teachers' needs, developers meetings focusing on the technology, and research meetings that sought to maintain a design-based research agenda embedded in this intensive application-oriented activity.

${ }^{41}$ As evidenced by this paper.
} 
existing activity systems and those that are envisioned by the reform effort. In communities of practice theory, alignment is a form of participation in which members of a community work towards a common objective by coordination of their activities without necessarily engaging directly with each other (Wenger, 1998). In activity theory, contradictions or tensions are conflicts between the constituents of an activity system that can be problematic but can also drive change (Cole \& Engeström, 1993; Engeström, 2001). In the present paper, we are extending these concepts of alignment and tension to relationships between communities and their activity systems as well as within them. We also adopt dualities from communities of practice theory as tools to understand the nature of contradictions and tensions.

\subsection{Envisioned Activity Systems}

Some of the activity systems envisioned by partners in the reform effort are illustrated in Figure 9. The existing activity system for the partner being addressed is on the right, and the additional or transformed activity envisioned for that partner by another partner is shown on the left. The ATR team seeks to engage teachers in reflective practice that is ultimately oriented towards student achievement (top left, Figure 9) but in which teachers' curricular resources and plans (specifically, assessment-driven, standards-based and technology-infused curriculum, implemented as situated inquiry learning) ${ }^{42}$ are the objects, and event-based professional development is the mediating tool. The LILT team as oriented towards teachers (Figure 7a), also seeks to engage teachers in an activity of reflective practice (second row, Figure 9) that shares the object and outcome objectives with the activity envisioned by ATR, but conceives of professional development as ongoing participation in a community of practice, in which community (community vertex, Figure 9) and an online environment (hnlc.org) are important cultural tools in addition to event-based professional development. ${ }^{43}$ Taking ATR as the subject (Figure 7b), LILT seeks to foster ATR's facilitation and mentorship of teachers' reflective practice in this community model of professional development. ${ }^{44}$

\subsection{Tensions Between Existing and Envisioned Activity Systems}

Some tensions may be noted between teachers' primary activity system and the envisioned activity of teacher reflective practice. In order to engage in this reflective activity, teachers are asked to reify their instructional practice in artifacts such as "unit plans" and "lesson plans" 45 so that their practice can become an object of inquiry in itself. This reification can be difficult for those who practice a more spontaneous approach to instruction (jagged lines (c), Figure 9) a participation/reification duality. For teachers who are not accustomed to critically examining their own practice, the focus on teacher performance (in addition to student performance) is a shift in practice. ${ }^{46}$

\footnotetext{
${ }^{42}$ See footnote 34 for our shared objectives. ATR's PD planning documents were oriented entirely towards the structuring of the time during which teachers were present at the face-to-face event. Meeting notes show that LILT PIs repeatedly guided ATR towards considering teachers' ongoing participation between events. See also footnote 36.

${ }^{43}$ See footnote 35 for documentation of LILT's CoP orientation.

${ }^{44}$ See footnote 36 for documentation of LILT's efforts to engage ATR in mentoring teachers' CoP.

${ }^{45}$ A lesson may be conducted in a single class; a unit is a coherent sequence of lessons.

${ }^{46}$ Early in the project, after the Hawai $i$ E-School conference in 2003, our project director reported that teachers did not see the reason for creating unit plans. Ironically, their most common question was "how can you help us match our curriculum to your standards?," which one can achieve through unit planning. However, a shift in practice did occur for some teachers. Online journal entries in 2007 indicate that teachers were beginning to
} 

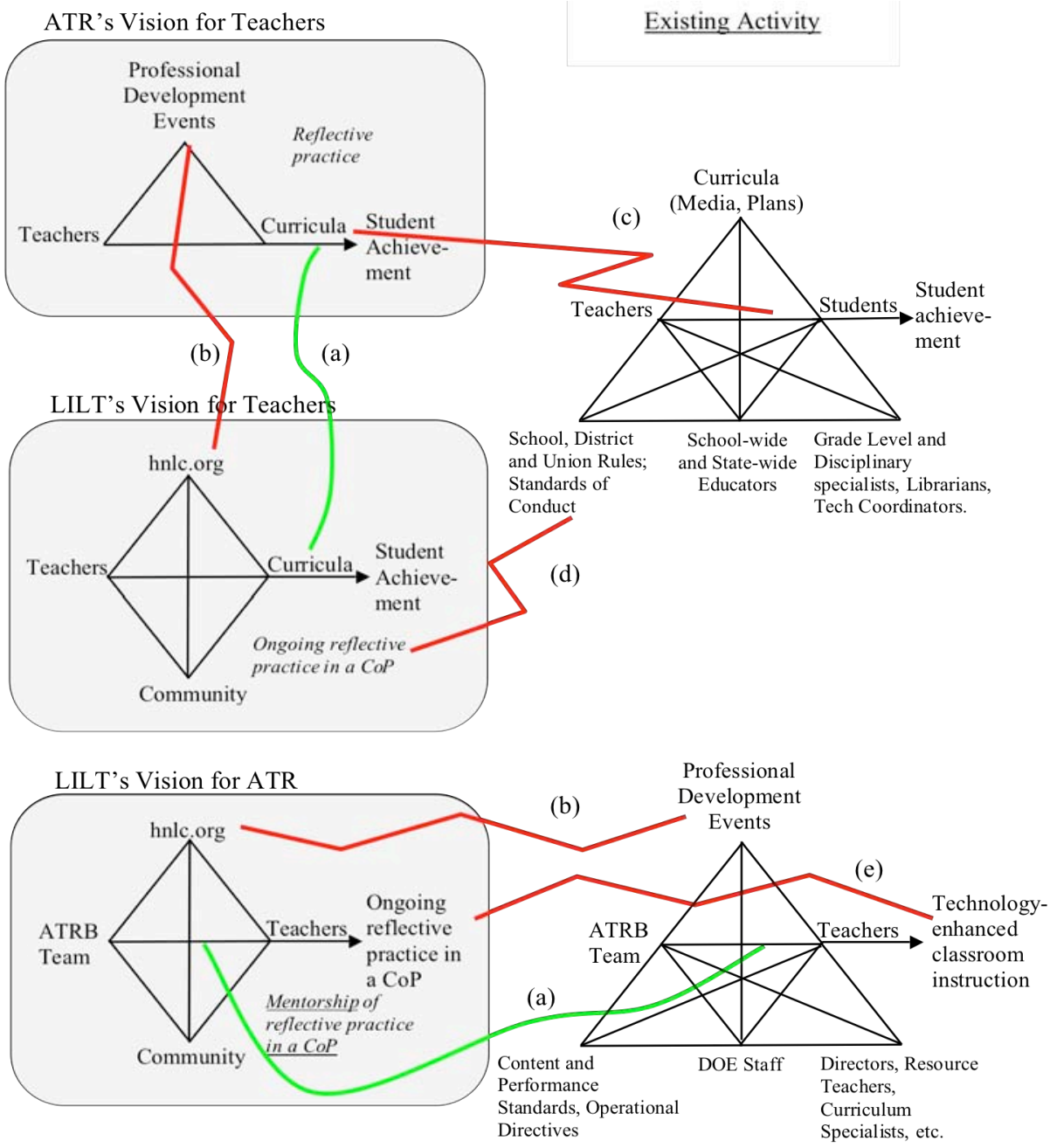

Figure 9. Alignments and Tensions in Reflective Practice Envisioned for Teachers. (a) Alignment between ATR and LILTs envisionment of teacher reflective practice (orientation towards curricula as object). (b) Mismatch in mediating artifacts emphasized in emergent activity systems sought by ATR and LILT. (c) Participation/reification tension between teachers' orientation towards students and the orientation towards curricula in the emergent activity systems sought by ATR and LILT. (d) Cultural and local/global tensions between teachers' norms of noncritical conduct and critical reflection in a community of practice. (e) Emergent activity system sought by LILT places greater emphasis on ATR's role as mentors of teachers' ongoing reflective practice in a $\mathrm{CoP}$, compared to ATR's emphasis on technology integration into the curriculum.

In the community version of reflective practice (central row, Figure 9), teachers are asked to share their instructional practice (reified as unit and lesson plans) with other teachers for co-reflection, which can be threatening in a culture where teachers seldom critique each other and especially when they do not know each other (Figure $9(\mathrm{~d})) .{ }^{47}$ This

look critically at their own unit and lesson plans. For example, many teachers mentioned how they discovered the importance of precisely worded rubrics to assess the learning task, and realized that even the rubrics from the HDOE standards toolkit were too vaguely worded.

${ }^{47}$ Barab, MaKinster and Scheckler (2003) discuss the influence of American culture and the culture of teaching. The influence of Asian cultures in Hawai i also includes hesitation to critique others. Loss of face is also a 
is one among several factors accounting for the lack of peer commentary on teachers' units throughout much of the project and the generality of the commentary where it existed. Recognizing this tension, we paired up school teams for peer critiquing. This team-to-team pairing was effective according to the online teacher journal reflections regarding this activity. They traded specific recommendations and raised questions regarding the unit plans in face-to-face exchanges and videoconferences. ${ }^{48}$ A tension in the local/global duality also complicates the sharing of instructional plans: the plans teachers developed to fit their situation may not make sense in other schools and classrooms, but the attempt to communicate one's plans for others can improve the plans. This duality also has a top-down manifestation: the statewide set of standards and other criteria and practices promoted by the professional development program may not make sense in every teacher's classroom, yet the effort to incorporate them may improve practice. $^{49}$

We have already noted that there is alignment between the ATR and LILT teams' envisioned activity systems for teachers (Figure 9(a)). However, there is also a difference in the mediating artifact: ATR focuses on its professional development activities while LILT focuses on technology-mediated community in hnlc.org (Figure 9(b)). The need to integrate hnlc.org with ATR's PD planning has been an ongoing issue in the project. The same tension is evident in a comparison of the LILT-oriented-to-ATR emergent activity system and ATR's primary activity system (Figure 9(e)). These tensions between planned professional development and practitioner discourse reflect both designed/emergent and identification/negotiability dualities (Wenger, 1998). In inviting ATR staff to use hnlc.org, we are attempting to implement a model that equates professional development with ongoing facilitation and mentorship of the reflective practice of members of a community of practice. Although the object of activity in the emergent activity system remains the same (i.e., teachers), we are asking ATR staff to use a different mediating artifact, online tools for collaboration and community support, and to orient their activity towards the outcome of an ongoing community of practice (Figure 6 (e)). The use of technology (hnlc.org) in itself is not a challenge for members of an Advanced Technology Research Branch, and ATR uses technology as a medium for teacher online learning in addition to helping teachers use technology for student learning. However, we in LILT found it difficult to match our conception of technology in support of a community of reflective practitioners with ATR's practices in using technology as a medium for distance learning. It should be noted that ATR promotes both reflective practice and learning communities. The issue is what these terms mean to different people, whether the concepts are integrated as reflective practice in a community of practice, and the consequent implications for the role of technology. Based on the analysis reported in this paper and elsewhere (Yukawa, Suthers \& Harada, in preparation), we worked with ATR to negotiate a shared conception of professional development and better integrate our offerings. ${ }^{50}$ Our teams began to work directly

\footnotetext{
factor. In 2007, a teacher online journal reads: "Admittedly, it was with trepidation that I entered into reviewing our work with a partner school. Why? Insecurity about the quality of our work."

${ }^{48} 2007$ Learning Fair presentations and online journal entries reflect overwhelmingly positive support for collegial exchanges. For example, the teacher of footnote 47 continues: "But it was such a productive meeting. Working with a school that had been in HNLC over a longer period of time was so helpful. Seeing what they had done was inspiring and gave us a yardstick by which to measure our own progress."

${ }^{49}$ At the 2007 Learning Fair, when teachers were asked to identify the three most important things they valued in the PD, they almost always mentioned learning how to use the standards.

${ }^{50}$ Beginning late 2005, several joint ATR-LILT meetings were dedicated towards developing a shared model of professional development.
} 
together, resulting in alignment through coordinated revision of our mediating artifacts (professional development plans and hnlc.org). ${ }^{51}$

\section{Mediation Between Activity Systems}

Having discussed relationships between the activity systems of pairs of partners, we now consider a trinary relationship, involving one partner as a mediator between the other two. Like any school system, the HDOE is a hierarchical system in which system administrators and staff produce reifications of "best practices" for replication-desired practices to be adopted by teacher practitioners. Yet, change in practice is not successfully imposed from outside (Osterman \& Kottkamp, 1993). Teachers and HDOE state staff need to negotiate a shared object (Engeström, 2001): the practices that are promoted by professional development. In an attempt to support HDOE's efforts towards best practices with a technological artifact, the LILT team inadvertently became an intermediary in this conversation, impeding direct negotiation between teachers and state staff.

The technological artifact in question is the "unit plan template," a web-based form for describing a unit plan. HDOE professional development staff wanted to guide teachers through an assessment-driven backwards-mapping approach to unit planning (Wiggins \& McTighe, 2001), and requested that the unit plan template enforce this process. According to this model, teachers should first identify the content and performance standards to be addressed and then identify the assessment instruments to be used to measure outcomes, before choosing student activities and the materials needed to support these activities. The first unit plan template we implemented provided a succession of screens that followed this script, while also constraining teachers' expression of their instructional plans to predefined fields. This scripted approach to unit authoring is the opposite of many innovative teachers' approach of identifying an engaging activity first and designing a unit around this activity: a designed/emergent tension. ${ }^{52}$

While this tension is a significant issue, the greatest problem lies in an imbalance of identification/negotiability: teachers were required to identify with an agenda that they had not helped to form. This problem was exacerbated by a trinary relationship between partners: the web-based unit template was controlled by the LILT team, and therefore served to place us in a mediating role between HDOE staff and teachers. HDOE staff (including state staff outside of ATRB) requested revisions in the template's structure, while teachers who were using the template expressed frustration with its inflexibility and noted incompatibilities with formats being used in their local school. ${ }^{53}$ When the

\footnotetext{
${ }^{51}$ Beginning in 2006, LILT research assistants met regularly with ATR resource teachers and teacher partners, setting up these meetings without going through HNLC PIs. These meetings resulted in coordination in both directions. For example, RA's email reports of these meetings show that ATR made plans to incorporate specific group and individual online participation as part of the requirements for obtaining PD credit, while LILT programmers initiated changes to enable ATR staff to manage workspaces and wiki-based unit plan templates.

${ }^{52}$ For example, early in the project an innovative teacher presented his work on having students study endangered endemic shrimp in anchialine ponds along the western coast of the Big Island using technologies such as probeware, digital microscopes, and laptops. Another project used similar technologies to track water quality in local watersheds. Teachers at other schools were impressed and wanted to implement similar projects in their schools. They began to develop unit plans with these core ideas; the identification of standards and learning objectives came later.

${ }^{53}$ For example, in May 2005 ATR informed the LILT team that a teacher at one of the participating schools had developed a unit plan template in Lotus Notes, and other schools were beginning to use it. However, on review
} 
LILT team tried to respond to one community, the other sometimes disagreed with the changes. ${ }^{54}$ Our role as designers of the artifact intended to bring the systemic reform agenda to teachers' practice placed us in the role of mediator of conversations about this agenda that should have taken place directly between HDOE staff and teachers.

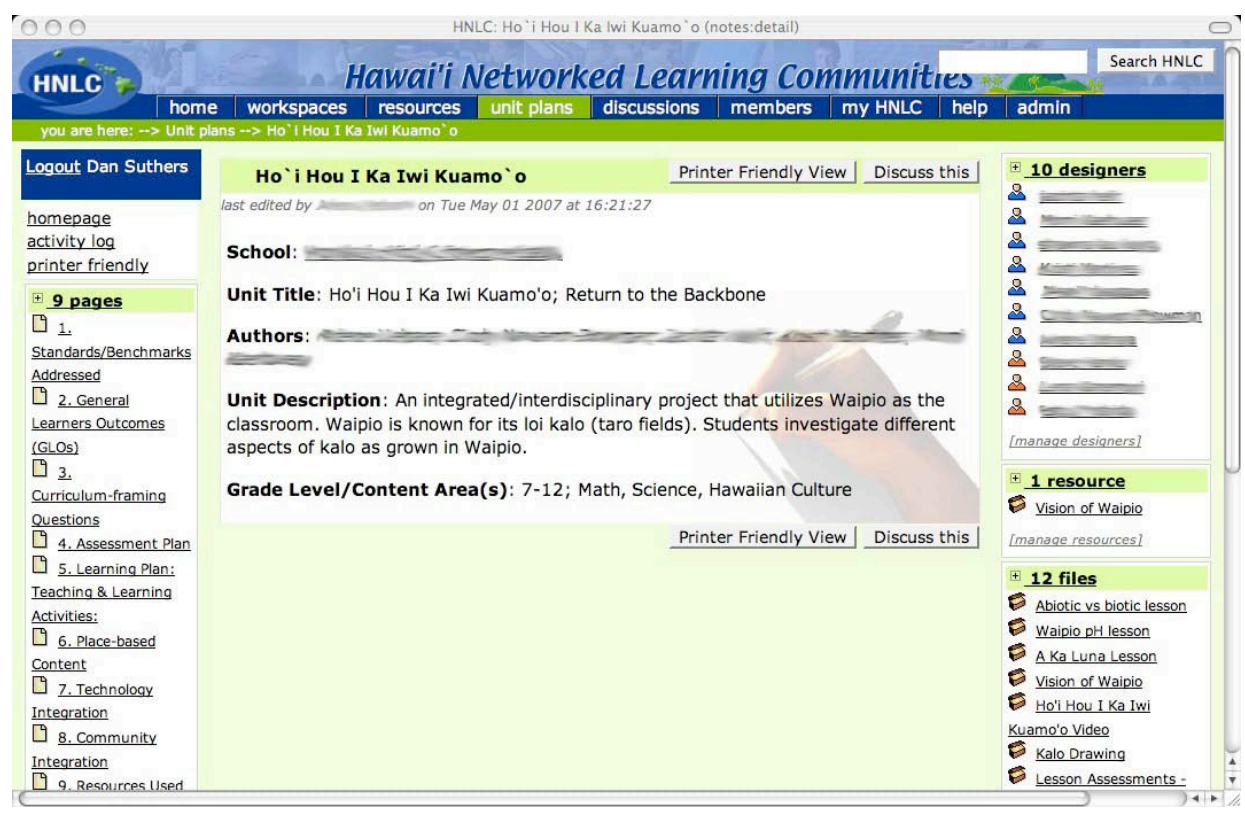

Figure 10. Wiki-based Unit Plan Workspace

ATR staff, recognizing in the 2004-2005 school year that the unit plan template was not working but reluctant to critique a tool into which LILT had invested much effort, advised teachers to use word processor documents that could later be entered into the template. Aware that this was happening, we realized the need for more flexible templates that teachers and professional development staff could negotiate and modify as needed. Accordingly, the form-based unit templates were replaced with wiki pages, tools organized in workspaces that also enabled participants to share related resources and discuss their plans (Figure 10). A collection of wiki pages are pre-defined for each new unit plan and initialized with default templates, but all participants, including teachers, can easily modify these templates or add new pages.

\section{Conclusions}

Sustainable changes in the practices of members of an organization may involve partnerships between different stakeholder communities, including those who are instigators of change. This is an explicit requirement of systemic reform as it has been promoted by the US National Science Foundation, and is often the case in school reform

we found that the template did not differ substantially from the HNLC template, other than lacking prompts for the roles of culture and technology.

${ }^{54}$ For example, after programmers had revised the template make it possible to jump into different parts of the template so that teachers could start with whatever initial ideas they had, the first author demonstrated the new software to state professional development staff, who insisted that teachers must choose the standards first. 
efforts that do not attempt to be systemic. Therefore, it is necessary to understand the relationships between the different communities involved. It has been said that partners would ideally function as one community, but until that becomes possible reform leaders must examine their practices to find alignments and potential tensions between partners. Activity theory, augmented with concepts from communities of practice theory, provides conceptual tools for such an analysis.

These tools were applied to understand a tripartite partnership in a school reform effort involving staff in a statewide school district, school-based educators, and the authors' team as university researchers. Examination of relationships between the activity systems practiced and envisioned by partners identified alignment between our objectives of reflective practice, along with tensions in the role of technology to support this reflection, individual versus collaborative reflection, and a risk unique to tripartite relationships: that one partner might become intermediate to negotiations that should take place directly between the other two. Based on these observations, we engaged our partners in re-examining our goals and strategies. As a result, in the most recent implementation year the working relationship between our teams improved greatly: ATR more fully integrated the LILT team's technology to support ongoing reflective practice by teachers, while closer interaction between our groups has enabled the LILT team to modify the tools to better meet their needs and teacher participation online has increased.

Clearly, activity theory and communities of practice theory are among the mediating artifacts of the practice of the LILT team (apex of Figure 5), and this paper constitutes evidence of our own reflective practice in a meta-activity as shown in Figure 8. Since these theories play such an important role in our own reflection, might they also serve as tools for engaging our partner communities in collective reflection? In general, it has been our experience that researcher's tools for reflection must be introduced to other communities with caution. They are excellent tools for our community, but pose a different conceptual ontology and set of concerns than those that are active in practitioner communities. ${ }^{55}$ However, we have begun to share our theoretical tools in joint ATR/LILT meetings and in presentations at the yearly teacher gatherings. For example, several years ago we provided the ATRB team members with papers on communities of practice and conducted a tutorial workshop on the topic. Subsequently, after Etienne Wenger visited the Hawai' $i$ DOE as a consultant and the HDOE administration called for the development of "learning communities" in the schools, one ATR team member appeared at an ATR/LILT joint meeting with a book on communities of practice. In our most recent project meeting, one ATRB member commented that they weren't ready for the tutorial when we gave it to them, but were ready now. In terms of the participation/reification duality, the theoretical reifications were not useful until there was sufficient experience (participation) to make them relevant. In terms of the activity theoretic model of Figure 6, the meta-tool with which one reflects on an activity must have an object on which to reflect.

We have only recently made an attempt to explicitly share ideas from activity theory with our DOE colleagues. The model of reflective practice shown in Figure 6 was presented at our yearly joint meeting. To date, we are not aware of an accessible introduction to activity theory oriented towards practitioners such as teachers. Yet we believe that a take-away message for practitioners is possible, and offer some suggestions by way of concluding this paper.

\footnotetext{
${ }^{55}$ Similarly for conceptualization of systemic reform: early in the project we tried to engage practitioners in discussions of the NSF Drivers for systemic reform, but teachers felt that the drivers were too abstract and disengaged from their day-to-day concerns with students.
} 
We have already summarized the need to identify potential alignments and tensions between partners in a reform effort. To accomplish this, the actual and envisioned practices of each partner must be characterized in a systematic way that can be compared. To begin, project leaders would document what members of each partner community spend most of their time doing. Towards what person(s) or entities is this activity directed? What are they trying to achieve? By what means do they try to achieve it? A deeper analysis can delve into division of labor. In what ways are members of the community specialized into roles for achieving this objective? What guides participation of each member in playing these roles? Answers to these questions enable identification of aligned objectives and tools (where they are the same), complementary contributions to the partnership (where one provides what the other is missing), as well as contradictions in objectives. In order to project into the future it is necessary to envision and elicit partners' visions for the transformation of these documented practices. What do members of a given community think that members of other partner communities should be trying to achieve, and by what means? In what ways are the objects, objectives, and means of each partner community aligned with the practices envisioned for them by other communities? In what ways do they differ from what is envisioned? What dualities might serve as sources of change and offer dimensions along which change is needed? How might other partners transform their own practices in order to further the transformations they envision for others? Conversations between partners driven by questions such as these, derived from activity theory but expressed in practitioners' terms, will go a long way towards avoiding or accelerating through some of the major struggles we experienced in our own partnership.

Finally, we conclude with a note on our adaptation of activity and communities of practice theories. The paper illustrates a theoretical point: communities of practice contain activity systems, and communities and their activity systems are nested. Because of the nesting, relations that are intra-system at one level of analysis are inter-system relations at another level. Therefore, concepts developed for analysis of internal tensions of communities and their activity systems can also be applied to understanding relationships between communities and their activity systems: intra- and inter- are two views on the same relations.

\section{Acknowledgments}

We are grateful to the numerous individuals who have contributed towards HNLC, including Vicki Kajioka (HNLC co-PI and ATRB director), Claudia Atta and Pat Donohue (HNLC project directors), and the other members of the ATRB and LILT teams for their hard work during the period reported in this paper, including Melisa Abregano, Wil Doane, Steve Hanks, Bruce Harris, Sam Joseph, Lena Kanemori, Sylvia Kaizuka, Viil Lid, Paulo Maurin, Heidi Salvador, Kyle Shodai, Ann Takazono, Joshua Wingstrom, Betty Yoshida, and Ryan Yoshioka. This work was supported by the National Science Foundation under Cooperative Agreement \#0100393. Any opinions, findings, and conclusions or recommendations expressed in this paper are those of the authors and do not necessarily reflect the views of the National Science Foundation, the Hawai i DOE, or the University of Hawai`i. 


\section{References}

Barab, S. A., MaKinster, J. G., \& Scheckler, R. (2003). Designing system dualities: Characterizing a web-supported professional development community. The Information Society, 19, 237256.

Barab, S. A., Schatz, S., Scheckler, R. (2004). Using Activity Theory to conceptualize online community and using online community to conceptualize Activity Theory. Mind, Culture, \& Activity, 11(1), 25-47.

Blumenfeld, P., Fishman, B. J., Krajcik, J., \& Marx, R. W. (2000). Creating usable innovations in systemic reform: Scaling up technology-embedded project-based science in urban schools. Educational Psychologist, 35(3), 149-164.

Cole, M. \& Engeström, Y. (1993). A cultural-historical approach to distributed cognition. In G. Salomon (Ed.) Distributed Cognitions: Psychological and Educational Considerations. Cambridge: Cambridge University Press, pp. 1-46.

Doane, W. E. J. (2003). Factors Influencing Use of a Web-Based Community Space for K-12 Professional Development. Unpublished M.S. Thesis, University of Hawaii, Honolulu.

Engeström, Y. (2001) Expansive learning at work: Toward an activity theoretical reconceptualization. Journal of Education and Work 14(1): 133-156.

Engeström, Y., Miettinen, R., \& Punamäki, R.-L. (Eds.). (1999). Perspectives on Activity Theory. New York: Cambridge University Press.

Fullan, M. (2001). The New Meaning of Educational Change. New York: Teachers College Press.

Harris, E. (2005). Key Strategies to Improve Schools: How to Apply Them Contextually. Lanham, MD: Scarecrow Press.

Hildreth, P. \& Kimble, C. (2004). Knowledge Networks: Innovation Through Communities of Practice. Hershey, PA: Idea Group Publications.

Huffman, J. \& Hipp, K. (2003). Reculturing Schools as Professional Learning Communities. Lanham, MD: Scarecrow Press.

Joseph, S., Lid, V., \& Suthers, D. (2007). Transcendent communities. To appear in Proceedings of Computer Supported Collaborative Learning 2007. Rutgers, July 16-21, 2007.

Kaptelinin, V., \& Nardi, B. A. (2006). Acting With Technology: Activity Theory and Interaction Design. Cambridge: MIT Press.

Leontiev, A. (1978). Activity, Consciousness, and Personality. Englewood Cliffs, N.J.: PrenticeHall. (Originally published in Russian in 1975.)

NSF. (2001). Rural Systemic Initiatives in Science, Mathematics, and Technology Education (RSI), Program Solicitation NSF 01-57, National Science Foundation. From http://www.nsf.gov/pubs/2001/nsf0157/nsf0157.htm

Osterman, K.F. \& Kottkamp, R.B. (1993). Reflective Practice for Educators: Improving Schooling through Professional Development. Newbury Park, CA: Sage.

Resnick, P. (2002). Beyond bowling together: Sociotechnical capital. In J. Carroll (Ed.) HCI in the New Millenium. (pp. 647-672.) New York: Addison-Wesley.

Schlager, M.S. \& Fusco, J. (2004). Teacher professional development: Are we putting the cart before the horse? In S. Barab, R. Kling, \& J. Gray (Eds.), Designing Virtual Communities in the Service of Learning. Cambridge: Cambridge University Press.

Schön, D.A. (1983). The Reflective Practitioner. New York: Basic Books.

Smith, M. S., \& O'Day, J. (1991). Systemic school reform. In S. H. Fuhrman \& B. Malen (Eds.), The Politics of Curriculum and Testing (pp. 233-267). New York: Falmer.

Suthers, D., Harada, V., Doane, W., Yukawa, J., Harris, B. \& Lid, V. (2004). TechnologySupported Systemic Reform: An Initial Evaluation and Reassessment. Proceedings of the 
Sixth International Conference of the Learning Sciences, Santa Monica, CA - June 22-26, 2004. pp. 537-544.

Vygotsky, L. S. (1978). Mind in Society: The Development of Higher Psychological Processes. Cambridge, MA: Harvard University Press. (Originally published in Russian in 1930.)

Yukawa, J., Suthers, D. D., \& Harada, V. H. (in preparation). Using Communities of Practice Theory to Analyze and Improve Collaborative Educational Projects.

Wagner, T. (2003). Making the Grade: Reinventing America's Schools. New York: RoutledgeFalmer.

Wenger, E. (1998). Communities of Practice: Learning, Meaning, and Identity. Cambridge: Cambridge University Press.

Wertsch, J. V., Del Rio, P., \& Alvarez, A. (Eds.). (1995). Sociocultural Studies of Mind. Cambridge: Cambridge University Press.

Wiggins, G. \& McTighe, J. (2001). Understanding by Design. Upper Saddle River, NJ: Prentice Hall.

York-Barr, J. et al. 2001. Reflective Practice to Improve Schools. Thousand Oaks, CA: Corwin. 